\title{
Social and policy networks in water governance
}

\author{
M. Ghorbani ${ }^{1} \&$ H. Moradi ${ }^{2}$ \\ ${ }^{1}$ Faculty of Natural Resources, University of Tehran, Iran \\ ${ }^{2}$ Faculty of Natural Resources, Isfahan University of Technology, Iran
}

\begin{abstract}
Water is a natural resource, fundamental to life, livelihood, food security and sustainable development. With a growing population and rising needs of a fast developing nation as well as the given indications of the impact of climate change, availability of utilizable water will be under further strain in the future with the possibility of deepening water conflicts among different user groups. In addition, there are inequities in distribution and lack of a unified perspective in planning, management and the use of water resources among stakeholders' relation to water governance. Rapid growth in demand for water due to population growth, urbanization and changing lifestyle poses serious challenges to water security. In order to successfully achieve water governance in arid regions, we should implicate an integrated approach in water policy making. Generally, in water governance present different actors (multiple actors), as social and institutional networks, that have various relations together in different scales. Planning, development and management of water resources need to be governed by a common integrated perspective considering local, regional, State and national context, having an environmentally sound basis, keeping in view the human, social and economic needs. In this project, our attempt, by using social network analysis, is showing the relationships between all the stakeholders in security and governance of water in several case studies. The analysis of a social network structure can be useful to analyze relations among actors in natural resources management.
\end{abstract}

Keywords: social network, policy network, water governance, social network analysis, stakeholders. 


\section{Introduction}

Water is a natural resource, fundamental to life, livelihood, food security and sustainable development. It is also a scarce resource. Water storage has a vital role to play in improving global food security and building resilience for adaptation to climate change. Furthermore large-scale impoverishment of aquatic biodiversity, ecosystem degradation and reductions in water quality are unaddressed 'side effects' in areas where water can be secured for human and economic uses. As the outcomes from Rio+20 and the last ten year strategy of united nation convention to combat desertification (UNCCD), challenges to the sustainability of global water security should be scrutinized. Of particular concern is the likelihood that the water-related Millennium Development Goals (MDGs) targets may not be achievable due to lack of funding commitments, and a failure of delivery mechanisms including water governance. A wide range of storage options are available, each with strengths and weaknesses. Because of the uncertainty associated with climate change, planners need to focus on flexibility in storage systems and give careful consideration to the sustainability, effectiveness and suitability of different storage types. There are further limits on utilizable quantities of water owing to uneven distribution over time and space. Ongoing land degradation, global climate change, increasing population, urbanization, and aspirations for better living standards present a challenge to natural resource sustainability. With a growing population and rising needs of a fast developing nation as well as the given indications of the impact of climate change, availability of utilizable water will be under further strain in future with the possibility of deepening water conflicts among different user groups. Low consciousness about the scarcity of water and its life sustaining and economic value results in its mismanagement, wastage, and inefficient use, as also pollution and reduction of flows below minimum ecological needs. In addition, there are inequities in distribution and lack of a unified perspective in planning, management and use of water resources among stakeholders relation to water governance. Issues related to water governance have not been addressed adequately. Rapid growth in demand for water due to population growth, urbanization and changing lifestyle pose serious challenges to water security. For achieving of successfully water governance in arid regions, we should implicate an integrated approach in water policy making. Generally, in water governance present different actors (multiple actors), as social and institutional networks, that have various relations together in different scales. Planning, development and management of water resources need to be governed by common integrated perspective considering local, regional, State and national context, having an environmentally sound basis, keeping in view the human, social and economic needs. In this study, our attempt, by using social network analysis, is showing the relationships between all of stakeholders in security and governance of water in several case studies. Then proposed policies will be implemented in each case study. The analysis of Social network structure can be useful to analyze relations among actors in natural resources management, and also several studies explained the application of social network analysis for concentrating on 
understanding the characteristics of social networks for solving problems in successful co-management of natural resource [1-6].

\subsection{Overall goal \\ (Long-term objective)}

1- Development of rural and urban societies and prevention of water resources distortion in sensitive ecosystems.

2- Achieving of successfully water resources management.

3- Prevention of poverty and migration from rural areas to urban districts throughout water supplement for local communities.

4- Protection and enhancement of food security.

\subsection{Project purpose}

1- Determination of criteria and indicators in sustainable water co-management (criteria such as social cohesion, institutional cohesion, collaboration, social power, policy power, etc.)

2- Measuring of criteria and indicators in relation to sustainable water comanagement.

3- Analysis and modeling of institutional and social networks effect on security and governance water.

4- Indication of opportunity and challenges in water security based on institutional and social networks.

5- Determination of operating solutions for sustainable water management.

\subsection{Outputs}

1- Providing of operating guideline for monitoring and assessment of water management projects in watersheds.

2- Determination of politics for achieving of sustainable water management in watersheds.

3- Determination of guidelines for movement toward sustainable development in rural and urban societies throughout water management.

\subsection{Beneficiaries}

- Local community inside and outside the considered watersheds.

- Urban societies located inside and outside considered watersheds.

- All of stakeholders in relevant with water resources in selected watersheds.

\section{Method}

Social Network analysis (SNA) is as a method for analyzing of social and policy network. Social networks are comprised of actors who are tied to one another through socially meaningful relations. These relations can then be analyzed for structural patterns that emerge among these actors. Thus, an analyst of social 
networks looks beyond attributes of individuals to also examine the relations among actors, how actors are positioned within a network, and how relations are structured into overall network patterns [5-7]. Data are analyzed using UCINET 6.244 software [8]. Visone software was implicated to show the graphs of relationships among actors in the network.

\section{References}

[1] Bodin, Ö., Crona, B., \& Ernstson, H., Social networks in natural resource management - What's there to learn from a structural perspective? Ecology \& Society, 11(2), pp. r2, 2006.

[2] Bodin, O. \& Prell, C., Social network in natural resources management, Cambridge University press, 2011.

[3] Crona, B.I. \& Bodin, Ö. What you know is who you know? Patterns of communication as prerequisites for co-management. Ecology and Society, 11(2), art7, 2006.

[4] Prell, C., Hubacek, K., \& Reed, M., Stakeholder analysis and social network analysis in natural resource management. Society and Natural Resources, pp. 501-518, 2009.

[5] Scott, J., Social network analysis: A handbook. Newbury Park: SAGE Publications. 2000.

[6] Wasserman, S., \& Faust, K., Social Network Analysis - Methods and applications. Cambridge: Cambridge University Press, 1994.

[7] Weiss, K., Hamann, M., Kinney, M., \& Marsh, H., Knowledge exchange and policy influence in a marine resource governance network, Journal of Global Environmental Change, 22 (1), pp. 178-188, 2012.

[8] Borgatti, S. P. \& Everett, M. G., Models of core/periphery structures. Social Networks, 21, pp. 375-395, 1999. 